\title{
Creativity, community, change \\ Functions of and motives for singing niggunim
}

\author{
RUTH ILLMAN
}

\begin{abstract}
ewish musical practices stemming from Kabbalah and Hasidic mystical traditions are currently the object of growing attention among a variety of different Jewish communities in Europe and North America, as well as in non-Jewish spiritual circles. As niggunim travel into new contexts, they are reframed and reconsidered in order to meet the needs and expectations of contemporary religious communities, characterised by a liberal and egalitarian, global and transformative religiosity. This article focuses on contemporary practices of niggunim - the (mostly) wordless melodies with roots in Hasidic Jewish traditions, sung, chanted and sometimes danced in preparation for, or as a form of, ardent prayer. The practice is seen as an example of the expressive, engaging, emotional and embodied forms of prayer that currently attract many Jews of different institutional attachments. The article seeks to explore the different functions niggunim are put to today and the motives which drive different people to engage in the practice. The analysis is based on ethnographic material in the form of in-depth interviews conducted among progressive Jews in the London area. As a conclusion, the article suggests an approach to contemporary niggunim practices that incorporates perspectives from both literature and ethnography in order to deepen the understanding of the motives for and functions of singing niggunim today.
\end{abstract}

\section{Introduction}

What is a niggun ${ }^{1}$ and why is it attractive as a way of expressing a Jewish religious identity today? What functions does the niggunim practice fulfill among contemporary, urban, progressive Jews and what motives inspire people to incorporate these traditional wordless songs into their communities nowadays? These questions lie at the heart of this article, which aims at exploring

1 In English, you find the alternative ways of spelling the Hebrew word: nigun/niggun as well as nigunim/niggunim. In this article, I have chosen to follow the spelling used in the Encyclopaedia Judaica, which is niggun/niggunim, unless I refer to direct quotes where an alternative spelling has been used. Also the spelling of other Hebrew words follows the recommendations of EJ, which means that e.g. the Hebrew letter $\pi$ is translated somewhat inconsistently either as $h$ or $c h$. 
niggunim as they are practised within a selected group of progressive Jews in London.

Put briefly, niggunim are religious melodies with roots in the Hasidic tradition that since the turn of the millennium have found their way into all sorts of Jewish communities around the world (Huss 2007; Summit 2000: 94-5). This development has interesting connections with the universal processes of change stressed by researchers of religion on a global level - often described as post-secular trends in the globalised, eclectic and highly digitalised religious landscape of today (Nynäs et al. 20 I 5). The rekindling of the niggunim practice in new contexts - sometimes referred to as neo-niggunim (Weiss 2009: 57-9) - can thus be linked to developments observed not only in Jewish communities, but in Europe and the USA at large. ${ }^{2}$ As a consequence, individual and embodied forms of worship connected to experience-based and emotional dimensions of faith are gaining ground at the expense of institutional and intellectual religious forms such as dogmas and formal authority (Huss 2007; Ochs 2007: I 7$)$. In this context, the wordless melodies, stemming from the Jewish mystical heritage, but adapted to the conditions and needs of the twenty-first century, offer an attractive alternative for many religiously curious Jews (Kahn-Harris and Moberg 201 2: IOI).

To shed light on this practice and illuminate the motives for and functions of niggunim today, ethnographic material has been gathered among Jews from progressive milieus in London. The functions of, and motives for, singing niggunim was touched upon as part of a comprehensive ethnographic field study that aimed at illuminating contemporary niggunim practices from many angles, including discourses of authenticity (Illman 2016) and emotional, embodied and ecstatic experiences (Illman 2015), as well as issues of liturgical renewal within progressive Judaism today. ${ }^{3}$ The material is composed of participant observation and in-depth interviews with ten people (five women and five men

2 Recent contributions analysing the role of sound and music in contemporary religious practice are e.g. Hackett 201 2, Hoondert 2015, Laack 2015.

3 The material was collected during two visits to London in July and November 2014. The informants were all tied to the progressive, urban and international Jewish milieu centred around Leo Baeck College (LBC; see their website <http://www.lbc.ac.uk/>), where rabbis and other professionals for the Reform and Liberal movements in the UK are educated. During my stays, I participated in services and meetings where niggunim were sung and conducted ten in-depth interviews with people involved in the practice. Thus, the research material is qualitative by nature and its creation has been guided by a striving to understand the points of view of the informants. On a self-reflexive note I want to add that the selection of research question naturally reflects my interest in and sympathies for the practices under study, but I am not myself involved in this practice. 
aged between 34 and 75 years old) involved in the progressive Jewish milieu in London, centring on Leo Baeck College and with a special interest in music, liturgical renewal and Jewish religiosity. ${ }^{4}$ In this article, the term 'progressive' is not used to denote a certain organisation but rather as an umbrella term for Jews of various organisational backgrounds, who are interested in developing liberal, egalitarian and renewed ways of living Jewish lives. The article focuses on individual understandings rather than official policies and thus among the interviewees are members of Liberal and Reform Judaism as well as Masorti and Orthodox Judaism.

What, then, inspires Jews such as the ones interviewed for this study to seek out meaningful religious practices in the mystical movements of the past? According to Jody Myers, several motives can be assumed; among these the opportunity to build an alternative, more open, flexible and immanent Jewish theology and to develop complementary forms of liturgy and religious practice (Myers 20 I I: I80-4). The wish to create a dynamic dialectic between creativity and tradition can also be mentioned: bolstering personal needs for selfexpression and religious experience while also satisfying a longing for historical embeddedness, structure and validity (Summit 2000: 153) Are these motives also relevant for the people contributing to this study?

\section{Niggunim: definitions and a historical background}

The roots of the niggun tradition go far back in Jewish liturgical history. Over the course of history they have been particularly associated with the Hasidic movement where they have become the subject of an entire theology of ardent devotion (Jacobs I 993: 68). The Hebrew word niggun (nign in Yiddish) is translated into English as 'tune' or 'melody'. Scholars assume that it can be derived from the verb ngn (נגן), which in Biblical Hebrew stands in piel (and is thus associated with an emphatic expression) and denotes 'to play a musical instrument' or 'to make music' (Jastrow 2004: 874). The Targum commentaries introduced the connection between the Biblical term נגן and a melodic performance of prayer (Elbogen I993: 382). In modern Hebrew the word is reserved for playing instruments, but in Hasidic contexts a niggun denotes a comprehensive musical unity (a melody) that can either be sung, with or without words, or performed on instruments (Gartner et al. 2007: 429). According to Ruth HaCohen, the word niggun bears connotations of 'authenticity', even 
holiness, as is the case among the Hasids (HaCohen 20I I: 439). It belongs to a group of several interrelated terms that are often used interchangeably in describing Jewish melodic traditions. Hence the word 'niggun' as such, simply means melody, but it belongs within a religious context and is mostly associated with a melodic study of the Torah (Summit 2000: I63-4). More specifically, niggunim are linked to Hasidic religiosity and the performance of repetitive melodies with plain syllables or mantra-like text fragments from the Torah or siddur (Weissler 20 I : 44). A niggun can even be called a 'pure melody' (Edelman 2003: 36).

There are many kinds of niggunim. Some have fixed texts from the Bible or the liturgy. ${ }^{5}$ Most characteristic, however, are the wordless tunes that are performed only to 'vocables' - literally, nonsense syllables - such as lay-laylay or $y a-b a-b a m$ (Bohlman 2008: 57). These are sung in a repetitive fashion, perhaps interrupted by cries of joy or lament. These wordless vocal melodies are often used 'as an extension of the existing liturgy, and serve as a prelude or postlude to the traditional prayers' (Avenary 2009: 48-9). Niggunim can be performed as song, instrumental music or dance, but the central point is that the tune and the singing itself form the core of the practice. The scarcity, or even absence, of words in niggunim is thus an apparent indication of the superior role of the melody: singing itself is more important than pronouncing certain words (Gartner et al. 2007: 427, 429). Most commonly, the repetitive element is accompanied by a gradual raising of pitch and increase in tempo so that the intensity of the tune becomes ecstatic (Avenary 2009: 50; Gartner et al. 2007: 428). Some niggunim follow rhythmic patterns while others have a freer rhythm (or alternate between the two) and are usually directed by the Rebbe (in Hasidic communities) or the song leader (Avenary 2009: 53). A. Z. Idelsohn writes poetically that niggunim are unique within Jewish music: 'These tunes have a taste of unearthliness - like a swaying mist which loses itself in infinity (en sof)' (Idelsohn I 992: 4I I).

Niggunim are often called 'Hasidic song' even if contemporary practitioners may not explicitly employ or identify with this heritage. Within Hasidism, a versatile Jewish spiritual movement that developed in Eastern Europe at the end of the eighteenth century, ${ }^{6}$ music became a way of expressing their ideology,

5 In the case of niggunim with words, furthermore, research has often shown that the texts are later additions, adapted to the original tunes (Weiss 2009: 62).

6 A detailed presentation of the multifaceted Hasidic movement cannot be included in this article, but can be found in, for example, Gartner et al. 2007, Jacobs I993, Rubinstein 1975 . 
and niggunim developed as a means of achieving spiritual elevation and ecstatic states (Bohlman 2008: xix, 80; Idelsohn I 992: 4I I). The Hasidic lifestyle was marked by ardent piety imbued with mystical motives such as achieving unity with the divine, sanctifying and purifying the soul, repairing the world through good deeds (tikkun olam) and even influencing the divine sphere by way of music (Idelsohn I 992: 4I 4; Rubinstein I 975: I7). At the social level, niggunim fulfilled the important function of creating community among the Hasidim (Rubin and Baron 2006: I2 I). The Hasids made joy the supporting pillar of prayer, and song, as a natural way of expressing joy, was accorded a central role in the religious practice (Bohlman 2008: xix; Edelman 2003: 36; Idelsohn I992: 4I I , 4 I 4; Smith 2010). ${ }^{7}$ The imperative to rejoice developed into an emphasis on enthusiasm and ecstasy - characteristic of Hasidic niggunim (Jacobs r 993: 68). Niggunim are associated with intensity and zeal as they 'are sung with a kind of ecstatic fervour by Hasidim' (Kahn-Harris and Moberg 201 2: Ior).

Border crossing, hybridity and an 'interplay of selfness and otherness' have always been prominent characteristics of Jewish music, Philip Bohlman contends (2007: 5). In Hasidic niggunim, these negotiations take place in the encounter between the sacred and the secular. Creativity and innovation have always been central aspects of a tradition that includes the active combination of high and low, secular and religious (Idelsohn I992: 4I5; Rubin and Baron 2006: I 2 I). All music was regarded as appropriate for rendering into niggunim and hence inspiration was sought in music from various sources far removed from the Jewish religious life (Gartner et al. 2007: 428). 'Rescuing' melodies from their exile in profane contexts and giving them a new sacred obligation hence became a religious duty (Edelman 2003: 35-7; Idelsohn I 992: 4I 7). Thus, 'all the doors were opened to the influx of foreign musical forms and styles, but they were remodelled' (Avenary 2009: 49). Singing became part of the aspiration to promote tikkun - repairing the world and hastening the coming of the Messiah (Summit 2000: 29, IOI). Thus, the niggunim practice 'emerged not from an anxious desire to tame the musical, but from a Jewish logic that ... embraces the music's radical potential' (Kahn-Harris and Moberg 20 I 2: IO2).

7 Even though the Hasidic communities of Eastern Europe declined at the end of the nineteenth century and were close to extinction during the Holocaust, Hasidism is certainly not a phenomenon of the past: there are many lively communities in Europe, Israel and the USA (Meir 20I0: 199, 2 I 5-I7). As a cultural form, therefore, Hasidic music is an active, creative and highly contemporary art form (Bohlman 2008: 68-9). 
Among contemporary Hasidim, one can find both the effort to preserve and document the musical heritage and the ambition to create new tunes inspired by the tradition (Bohlman 2008: 68-9). Today, one also finds a growing use of niggunim among progressive, liberal Jews with an interest in expressive and embodied prayer forms (Ochs 2007: I7, 26; Weissler 201 I: 53). A burgeoning interest in the niggunim tradition had already commenced during the r 960 in the USA as part of the so-called Jewish Renewal movement, which was part of the larger countercultural movement of that time (Ochs 2007: 37; Summit 2000: $42-3$ ). Today, the tradition is alive within many branches of Judaism as part of a larger upswing in explorative, emotional and embodied Jewish practices (Levine 2009: 4-5). For this contemporary context, which is the focus of the current article, Vanessa Ochs offers the following definition:

The nigun is a Jewish spiritual melody often sung with universal sounds, rather than words. Initially used among Hasidim to warm up for prayer and also as a prayer in and of itself (Ochs 2007: 37).

In this article the term 'niggun' is used in line with Ochs's suggestion: to encircle a special kind of religiously significant set of tunes associated with Jewish religiosity, rooted in Hasidic religiosity but currently developed and adapted in a variety of Jewish settings, and the focus is especially placed on wordless melodies. As noted above, the functions of niggunim within traditional Hasidic milieus were to prepare for, or form part of, prayer and to create community. By creating an interplay between sacred and secular elements, niggunim offered a practice that through its wordlessness and intense character highlighted the emphasis on the soul's intention beyond intellectual capacity, ardent devotion beyond rational reasoning, and abundant joy above all. Theologically, the motives reflect the mystical heritage of the Kabbalah, which was a tendency within Hasidim: repairing the world, bringing forward the coming of the Messiah and strengthening divine presence (shekbinab) in the world. Against this backdrop, it is time to turn to the ethnographic accounts to analyse what functions and motives are attached to the niggunim practice in this context.

\section{What to do with a niggun?}

Many of the interviewees are cantors or prayer leaders in various Jewish settings and reflect on the practicalities around niggunim in relation to their communities rather than their personal family sphere. In the following, therefore, 
'we' commonly refers to the community in which they are active. The interviewees give varying answers to the question of whether they use niggunim in their religious practice. Most say they use them to some extent, as Dinah: 'Niggunim in the very strict sense of being melodies without words, the largely Hasidic origin, we don't do it a lot'. Nevertheless, she contends, her Reform community often uses prayers that are 'niggunim-ish', that is:

... where part of the melody itself appears niggun-like ...; it starts off as though you're singing a niggun and then you actually insert the words and then you lay-lay again at the end. I would argue whether that's strictly speaking a niggun, but it feels influenced by niggunim.

Similarly, Sarah, who works as a Reform cantor, says: 'We don't use them that much [but] we use them every so often.... I feel as if my niggun repertoire is pathetically small [laughing]'. Among the interviewees, the Masorti cantor Rebecca is most enthusiastic about niggunim: 'It's really wonderful and we use niggunim a lot', she exclaims. Both Miriam and Daniel, on the other hand, say they never sing niggunim.

Micah, who has a past involvement in the Hasidic Chabad movement but now works as a Liberal rabbi, says he does not have many opportunities to use niggunim anymore. In addition, he does not find it as urgent or attractive as before: 'There's just too many other more important things to do with the time'. Hannah says her Reform community does tend to sing melodies without words 'in a kind of Hasidic style with ya-ba-bam or lay-lay-lay', but that not many niggunim are included in the services: 'It's not something that we never do; we just don't do it very much, because it's more formal'. However, most interviewees agree with Daniel (born in the r 950s and a member of an Orthodox synagogue), who says that overall this form of singing is 'more visible than it was when I was young, certainly ... so it's grown, very much grown'.

\section{Niggunim are teachable}

The interviewees associate niggunim with spiritual and mystical values such as experiencing a connection to the divine and sanctifying one's own hectic life, but above all, they are seen from a practical angle. From a pedagogical point of view, wordless niggunim have many advantages. In congregations where members are not confident in Hebrew, niggunim offer a viable option: the melodies are simple; they are captivating and easy to join in with, regardless of Hebrew 
skills or musical proficiency. ${ }^{8}$ Niggunim are, to use Daniel's term, 'teachable'. Sarah calls niggunim a 'teaching tool':

I find that they're helpful for a couple of things. One on a very technical level: niggunim are a great way to teach. If I want to introduce a new melody for a piece of liturgy that's halfway through the service and I don't want to stop the service to teach it, I'll teach the melody without words, as a niggun. [And when] they know the melody I just fill in the words.

Similarly, Rebecca uses niggunim to teach new melodies, however not revealing that she is actually teaching something new 'because then you've broken the flow of the service'. If you bring in the new melody in the form of a niggun 'you hold the energy' and it works every time, she concludes. 'Rather than as a prayerful device [the niggun] becomes more of a leadership device, or pedagogical device', Dinah agrees. She thinks niggunim are useful for meditation because 'there's something very natural about it; ... to have a melody to hold on to'. A melody, you can 'take outside of the service, the formal structures of prayers as well, and carry with you for the rest of the day, that's very helpful'. Adam argues that niggunim get people to sing 'almost without thinking, the way children will sing when they're around music'. Niggunim also function as an invitation: 'I think it gives the congregation the permission to sing'. In order to function in that way, however, the niggunim must be uncomplicated, Micah concludes: sometimes you have to 'simplify it ever so slightly to make it easier in case people wanted to join in. Some of the very fiddly bits I just simplify'. Yet, teaching is not the right word to use, as Hannah ponders:

When I 'teach' - I'm saying it in inverted commas, niggunim - I don't teach them. I say to them: I will sing it until you can join me. And when everybody has joined and we've sung it through, then everybody knows it. It just feels to me alien to the soul of a melody to [teach it]. I think there is something about niggunim that has a life of its own.

There are definitely trends in niggunim singing, David concludes: some years, certain melodies are sung to the extent that they start 'getting on everybody's nerves'. In a similar vein, Dinah jokingly says: 'Niggunim without words

8 In order to demonstrate this point, several of the interviewees introduced niggunim during the interviews and made me sing along - a method that usually functioned very well. 
of any meaning, just the lay-lays, they have that kind of earworm quality to them, you know, where they get stuck in your head'.

\section{Structuring time and creating moods}

Among the functional qualities of niggunim, the interviewees frequently mention their ability to structure time and create different moods, for example 'getting people in the mood for Shabbat', as Micah says. Hannah describes how her family always starts Friday night 'with a niggun that we used to sing in my home'. Just two notes into the niggun she feels 'it's bye-bye week, hello Shabbat'. Adam and Miriam describe how wordless niggunim can be used to separate secular time from sacred time as well as marking the transition from one section in the liturgy to another. Furthermore, Miriam argues, niggunim are apt tools for creating an atmosphere - of joy or sincerity, remembrance or assurance, depending on the circumstances. In fact, she claims: 'I would completely instrumentalise it':

What do I do with niggunim? I use them very functionally, for example to create community in the beginning of a service: people come in; they are talking, and if I want us to start together, I will use a niggun and often people know the melody so they pick them up very quickly. ... Then I would use them to introduce the time ..., to create atmosphere but also time boundaries, so that you know when it is Hanukkah or Kol Nidrei or ... [and] then, I use them to keep people silent [laughing]!

Dinah follows the same line of thought, saying: 'They might be used rather than saying: "OK everybody, it's time to start up". Somebody might just start by humming a niggun clearly as a device to bring people together.' Sarah agrees: 'It's a great way of getting people settled in and settled down for the service'. Starting with a song is, according to her, a soft entry into the space of prayer:

If I start singing [a niggun] and I just do it three or four times, by the second time people will have started to quiet down, by the third time they're silent, by the fourth time they've joined me. And I don't have to say a word. ... So starting a service with music is a real signal that, OK, this is something different now, I'm not talking at you, we're in this together. ... You don't want to be patronizing but it's much easier, much nicer, to know that it's time to do something when you sing it. 
Sarah also claims niggunim are apt to be used as a bridge, especially for going from particularly upbeat texts that we need to transit into something a little bit more gentle'. Miriam, too, points out that niggunim can be used 'to prepare people to change an atmosphere'. Rebecca would use niggunim both for 'introductory ends' and as continuations of prayer: 'If we've had a prayer where people have enjoyed singing it and you don't want it to go, you like it but you've run out of words, so you just carry on singing the tune'. This way, you do not have to 'come out of the magic all of a sudden', but can dwell in the prayer atmosphere even after the words are finished. Hence, a niggun is useful for creating and upholding sacred time, a way of 'settling in and getting ready' for Shabbat, as Sarah says: 'I don't do this on a normal day so this is how I'm expressing being Jewish and being here and separating from the rest of the week'.

As mentioned above, the niggun is referred to as what Rebecca calls 'a mood creator'. The mood can be meditative and peaceful or jolly and lively depending on the niggun. This includes 'building up an atmosphere' and 'creating an emotion' in the service, as Miriam and Micah clarify. The niggun, Sarah concludes, 'keeps us going, and it keeps us building up this fervour of getting ready for the service, which is a lot of fun!' Dinah refers to niggunim as 'very good shortcuts to a particular space', and says: 'If I as a service leader want to trigger a particular state, emotion, communal memory or something, [a niggun] will be a much faster way to get there'. Rebecca points out that in her view, 'Judaism is not really a religion of belief as much as a religion of doing'. The physical activity of singing together, without words, underlines this and creates energy, which is felt rather than heard. As mood creators, niggunim are flexible tools, Hannah contends - the same tune can be sung with or without words; it can change and transform:

The same melody could be a steiger, a kind of a meditative pouring of the soul, and it can also be a freilache, a joyful [tune]. It depends on how you perform it; there're lots of niggunim that you can sing slowly and they have one mood and you sing them fast and they have a very different mood.

\section{Creating community - but also distance}

As noted by, for example, Jeffrey Summit (2000: 34) and Martin Hoondert (2015: I3I), participatory singing can offer transformative occasions where experiences of unity, community and sharing flourish on a deeper level. This aspect of niggunim is accentuated in the interviews. Niggunim 'give a community something to do together', Daniel states. Miriam adds that the advantage 
of the niggun is that you can join in easily, which creates community. Adam presents a similar view: 'The whole idea behind [the niggun] is that everybody is singing it. So people coalesce around it.' Micah sometimes presents niggunim as a soloist in concerts and gatherings, but emphasises that 'just to stand and perform a niggun feels somehow wrong'. He would much rather sit in a circle together with others and encourage them to sing along: 'Niggunim are not solo performances, it's very much everybody singing together'. Therefore, Sarah says, a niggun 'helps to connect with the people around', and continues:

It's hard to speak something together, but it's really easy to sing something together. So the rhythms and the melodies ... it's a point of connection between me and the people that I'm with now as well as the people in tradition, in history. It's a powerful form of expression.

Many of the interviewees stress the importance of involving everyone in the service - not merely having professionals who perform the music and congregants who are spectators. 'People generally want to be participants and not audience', Rebecca claims. In her view, this change towards greater participation shows that religious sentiments are changing. Today, people seek prayer experiences that are tangible and intimate: 'We want to enable each other not just to sit there like wooden posts; we're all involved in it'. In the service, then, the niggun helps you to 'stay engaged and stay a part of things', Sarah claims. 'I want to be part of it', Dinah agrees, but also points to the need for balance and rhythm:

Normally I love singing along the service. ... I want to participate. [But] I think services do need to have light and shade, a balance, and so there is a place for a solo here, group participation here, maybe a choir. ... Because I want to participate, it doesn't mean I have to sing every single thing.

Despite these positive assessments of niggunim singing and its adaptation to contemporary progressive services, several informants also describe uneasiness with wordless melodies. Miriam has made a conscious decision not to tap into a heritage that she does not feel is her own.

I don't use [niggunim], deliberately not, because I'm not connected. I don't want to connect to that Eastern European shtetl world. Because we live in modern Europe, we live in a time where we do not live in ghettos, we are part of the normal everyday world, outside, part of society. So why should I use this tradition, that comes from something that I cannot connect to? 
Daniel presents similar motivations: 'I don't do it; not part of my tradition. I didn't grow up doing it. So I just see it going on, it can be nice.' Dinah clarifies that singing niggunim today does not entail your subscription to the theological standpoints upheld by the communities that developed them. There is a clear differentiation between classical and contemporary motifs for singing niggunim, but it is far from watertight, she claims: many people within progressive communities have colourful Jewish backgrounds and may choose to combine motives and beliefs from different sources in their personal lives:

In the Jewish community, I think it's very likely that most people have a number of different kinds of Jewish experiences, and therefore, when I sing the niggun in my Reform synagogue, am I really thinking about bringing the Messiah back? Maybe not, but that would be to discount the likelihood that a lot of people might well know that information from some other part of their Jewish life experience.

Others describe a more practical uneasiness with niggunim. Adam, for example, says he would use niggunim if asked to, but generally prefers prayers with words. 'The idea is that people will be comfortable singing [niggunim] because they don't have words, but that's not my experience', he claims:

What I've found is that congregations are generally a little bit uncomfortable singing la-la-la.... They just don't know quite what to do with it. So I find that they do better with tunes that have words, but simple [Hebrew] ones. But it isn't about what's being said, it's that it's easy to sing [with] words, there's some feeling of being attached to them as opposed to la-la-la.

For the same reason, Dinah says she 'couldn't have a prayer experience that was only niggun, but as part of a service it can be powerful'. Thus, she holds: 'I'm not averse to them; it's a lot to do with how it's used, when it's used, why it's used'. Micah also asserts that 'the whole question of singing niggunim and creating community is a tricky one'. Like Adam, he doubts that singing without words is easier:

It's actually not so clear, not so simple. Because singing with words, if you can get the words across to the people, actually helps to anchor the melody and helps people to associate syllables with notes and get the shape of a melody. Singing without words, it can be much harder for people to get the shape of a tune and fix it in their minds. And also, if people are not used to 
singing to nonsense syllables it can be very uncomfortable at first, ... a little ridiculous, a little strange and artificial.

Others, on the other hand, think that wordless singing comes naturally in Jewish communities. 'Our community is used to the feeling of a niggun', Sarah says: 'Because we have this embedded culture of niggunim ... we're used to it, we love it, we like to sing and if there's no words it makes it easier to sing.' Nevertheless, she adds: 'There's certainly some people [for whom] niggunim feel very foreign ... they don't necessarily know that there is that connection but it's amazing how quickly they grab on to it'. Hannah is even slightly upset by the thought that niggunim are experienced as insincere:

I think that people, who are uncomfortable singing [niggunim] because it's childish, are very far removed from the Jewish community, because if you are part of the Jewish community, you grow up with it all the time. Have you actually met people, who are steeped in the Jewish community, who'd say that they feel it's childish? ... I've never experienced it, I think we all grow up very comfortable with that kind of singing, it's part of our culture, part of our tradition. It wouldn't occur to me to think this is childish.

\section{Musical creativity}

The presentation above shows that the interviewees largely experience and discuss niggunim in functional terms rather than in terms of a theological or mystical heritage. Thus, the practical elements, what a niggun can do, are brought out as more relevant than the wish to adopt a certain ideology. Seen as a function, wordless singing is open to a colourful array of creative practices. As noted by Summit, contemporary musical choices of Jewish religious music can include a variety of influences, such as Sufi chants and Buddhist mantras, folk music, popular music and much more (Summit 2000: 4). Similarly, several of the interviewees describe at length how they go about creating and adapting wordless tunes as prayer leaders or cantors.

\section{Creating innovation by adapting tradition}

New niggunim are often created by adapting and developing elements from the Jewish tradition. Miriam describes how she creates new niggunim spontaneously, based on traditional motifs: 'There are lots [of melodies] which everybody knows', she says, they are easily picked up because 'they are so common 
they are almost boring!' Another source of inspiration for Miriam is the traditional cantillation mode, nusach, which forms the chanting of prayers in traditional synagogues:

What I do is I create tunes by using the nusach of the moment of time. ... But if I want people to join it has to have a rhythm and regularity. It's not a niggun, it's just something made up to wake you up a bit: Are you with me here in this room? [laughing]

Daniel describes how he incorporates tunes from different spheres of the Jewish world in his prayer life: 'If there isn't an Ashkenazi tune I'll use a Sefardi one. And I even invented one or two, or adapted them.' According to Rebecca, cantors should feel free to develop the tradition creatively, relating to things that are currently going on in the world and in the community. Sometimes 'I make it up on the spot'; as she describes it:

That's a lovely way of using niggunim, and I do, and it doesn't have to be something that was written down or handed down to me, I can make up anything, I'm a hazzan, I know what to do with it! ... And it's spontaneous; you don't have to write something down.

It is important that all melodies you bring in suit the purpose and the atmosphere of the particular service and moment, as Sarah emphasises: new tunes need to fit into the flow. 'There has to be a way: fast and slow and loud and soft, but purposefully.' As her sources, she uses material from her cantorial training, but also consults colleagues for advice.

With his background in the Chabad movement, Micah clearly draws on the traditional Hasidic repertoire in his practice. Niggunim are a 'very prominent part' of the Chabad movement, he explains, and certain niggunim are especially close to his heart so that he has preserved them in his religious practice even while renouncing the Chabad theology. Thus, he introduces his favourite niggunim by telling their story: what Rebbe they are ascribed to, their structure, their use in the Chabad community and their theological connotations. Niggunim thus remain important for Micah, even if he does not use them as widely as before. Some twenty years ago, when he first joined the Liberal movement, niggunim were new and exciting:

I was in quite a lot of demand, to come and sing niggunim.... There was great curiosity to find out about this relatively unknown world. It's become 
much more mainstream since then.... A lot of younger rabbis who have absorbed neo-Hasidic approaches when they've gone to study in Israel or in the United States, where there are very vibrant Jewish musical cultures that often involve niggun-type singing, whether it is real Hasidic niggunim or modern composed niggunim, of which there are a lot.

Most of the Hasidic niggunim Micah learnt the 'organic way', that is, 'from singing with people, just listening and joining in'. However, he also set out to learn more on his own, consulting records and musical transcripts. Nevertheless, today Micah has his own, personal way of singing niggunim. What syllables are used is a question of personal taste, he says: 'I usually start with lay-lay-lay but then introduce other sorts of syllables depending on the shape of the music and the feeling'.

Inspiration from and encounters with other religions

Some informants gladly explore melodies from outside the Jewish tradition in their development of niggunim. 'I don't believe that all of our sacred music needs to be composed by Jews', Sarah says. Thus, she is open to experimenting with crossover concepts such as 'Yoga Tefillah'. Rebecca is also open to finding inspiration 'from everywhere'. In her view, the function of the melody is more important than its background. 'We also bring in music from other religions; we've got a lovely Sufi chant that we use. I can use that as a niggun, and I do sometimes. Why not?'

An illuminating example of crossover creativity is given by Hannah, who during the interview sings the melody of a well-known Finnish folk song ('Taivas on sininen ja valkoinen') in niggun style, chanted to the characteristic syllables lay-lay-lay. 'I call it niggun', she laughs and describes how she learnt it years ago from a Finnish friend: 'I have it, for me it's a niggun'. Hannah asks me, the interviewer from Finland, to explain the words, which I do: it is a melancholy text about longing, loneliness and heartache, revealed only to the stars in the sky and the deep forest. 'And you use it as a niggun', I ask, surprised and intrigued. 'I could use it as a niggun; if I came to Finland, I would sing it', Hannah responds. For those, who know the words, the niggun will tap into the emotion of the existing song 'but it will add another layer; you will suddenly see it fresh as just music, with ya-ba-bam...'

I later retell this story to Miriam, who responds by calling it a 'good example' of how tunes can be adapted into the liturgy in a sensitive and meaningful way. For example, she reflects, it could be used in Finland on Yom Kippur: 'In the 
context of missing, of longing for someone, if you start with this niggun', you may recognise the folk tune and connect to its atmosphere, perhaps helping you to formulate your prayer: 'God, I'm lonely, be with me'. Yet, creating niggunim based on traditional melodies from other contexts is a delicate task, Miriam emphasises: 'When you do this deliberately, it can be enormously powerful', she contends; but she also describes examples where vernacular tunes have evoked shock and resentment when used in the liturgy due to the connotations they carry. 'I think ignorance is something that mustn't happen', she states; you have to know the background of the tunes, their undertones and original context to be able to use them appropriately as niggunim. Thus, in her view, Christmas carols and national anthems are examples of melodies which are unsuitable as niggunim.

Hence, the interviewees define the limits for innovative musical borrowing in different ways. While Rebecca feels comfortable with integrating Sufi chants and Dinah mentions participating in Sufi dikr, Adam would not use melodies that are 'devoid of any connection to Jewish tradition, however defined'. Daniel, on his part, mentions Buddhist mantras as an element he feels sceptical about integrating into Jewish prayer. However, interreligious encounters are presented as a context in which niggunim are especially suitable. Niggunim are 'wonderful in interfaith work', Rebecca exclaims; 'It's another way of embracing and learning'. Dinah concurs:

One thing about wordless melodies is they're very convenient for interfaith work. ... Nobody gets too worried about it because they're not imbued with meaning in the same way [as melodies with words]. And they can be very handy in that kind of space.

Micah often uses niggunim in interfaith contexts because he believes that melodies without words can 'speak to people across religious divisions' as a spiritual technique. In interfaith work, Hannah contends, the niggun is 'an equalizer; it cuts through all the cultural [differences] and the languages'. Similarly, Daniel describes the use of Jewish music in general, not specifically niggunim, in encounters with the secular world:

We use song and music as a way of integrating people, who actually have nothing to do with religion at all, into the activity of prayer, and via the activity of prayer into some understanding of what Shabbat might be about, and what prayer might be about. And it's quite complicated things; it's about explaining the nature of the world. 


\section{Mysticism and ecstasy in a critical light}

As shown above, the interviewees who describe their experiences of engaging in niggunim singing in progressive milieus in London convey a largely practical approach. They evaluate it in relation to the benefits it offers, the ends it meets and the functions it fulfills. In most cases, niggunim are not perceived narrowly as a historical phenomenon tied to the Hasidic heritage, but rather as a broad, functional category that includes wordless songs that meet the desired ends of the communities: facilitating equal participation, creating atmosphere and connecting people with various backgrounds. Thus, the motives for engaging in wordless singing seem immanent rather than transcendent and expressive rather than esoteric or mystical.

The mystical aspects of wordless singing are mostly discussed in terms of personal religious experiences as facilitating self-awareness, wholeness and well-being, as well as offering emotional and embodied forms of prayer. ${ }^{9}$ The interviewees know the Hasidic history of niggunim and the Kabbalistic motives involved, but predominantly choose more immanent ways of describing their own practice. Micah, whose attachment to Chabad Hasidism was mentioned before, contends that niggunim are, of their very essence, a mystical practice, even if they are seldom used in that way today: 'I think of it as an inherently mystical practice, singing niggunim, but for most people in progressive contexts it's done in a fairly non-mystical way'. This description of niggunim in the progressive Jewish communities of today is emblematic of the opinions aired in the interviews: 'It's of course a completely different approach to niggunim than [the Hasidic], a very functional approach', Miriam concludes.

Thus, the mystical motives are often left aside: there is seldom mention of bringing back the Messiah, redeeming the divine sparks entrapped in the material world, sacralising worldly tunes by adopting them as niggunim, or influencing the divine by means of singing. One aspect of the mystical heritage, which most interviewees allude to in a negative way, is the ecstatic character of certain niggunim. Embodied, engaged and emotional forms of prayer appeal to the interviewees if they are meditative and grounding - ecstatic traits are approached with hesitation and suspicion. Many of them feel uncomfortable with cheerful, happy and energetic singing, which may also include clapping or dancing. As David states: 'When niggunim end up in ecstatic frenzy, clapping and dancing ... when they are framed in that [overtly cheerful] lay-lay, I just can't ...'. Dinah agrees: 'Some of the stuff that I definitely don't like is what we 
tend to refer to as the happy-clappy scene. ... I don't like things that get too charismatic. There's something that feels quite artificial about it to me.'The 'happy-clappy', Dinah specifies, is the excessively cheerful and ecstatic:

A service where you are being deliberately led by a service leader to stand up, to clap, to sway, to feel the need to dance, to be dragged around the room in circles to some sort of heightened emotional experience that is meant to be only positive feels Evangelical to me; and I'm very mistrustful of them, it feels very Christian. It just does zip, nothing for me.

These kinds of experiences are important to many people inside as well as outside the Jewish world, Dinah admits, but personally, she feels sceptical: 'Building a safe environment for prayer is important to me, and that can be an environment where people are enjoying themselves, but not to the point where they want to fall on the floor and speak in tongues ... [laughing]'. Daniel shares her suspicion of practices that 'may not feel dignified'. Adam, on his part, feels uneasy about dancing:

It's not my sort of thing. I'm just not one of those people. There's a lot of people, who are and for them it may be completely authentic, that they feel this need to move and they do [but] I'm not comfortable with that.

Other interviewees are more positive concerning the so-called 'happyclappy scene'. Sarah laughingly says that 'happy-clappy' was a positive term when she grew up in Canada; only in Britain has she learned the derogatory connotations of the phrase. Dancing is seldom incorporated in her synagogue though: 'That doesn't mean we are not interested, it means that it's scary and it's hard; I think that's probably one step too far for some people'. Rebecca, on her part, is more positive: 'Why should I not be happy?' she replies: 'and clappy - we haven't done a lot of clappy; I'd love to bring in some drums!' She is also keen on dancing 'on the occasions that merit it; it has to be spontaneous'. Such practices need to stay within certain limits, however: 'I'm not saying we have to throw inhibition completely to the wind; you wouldn't want people to do things that wouldn't be acceptable'.

Thus, a middle way between embodied, energetic participation and meditative, sincere prayer is called for. Actually, this balancing is reflected in the basic structure of most niggunim, Micah contends: There are 'meditative niggunim' and 'jolly-dancing type of niggunim' but most would tend to be 'in-between niggunim [with] a bit of both in them'. Nevertheless, he regrets that the more 
complex niggunim are seldom used in service because the singalong quality is lost: 'To use niggunim to get people together, they always have to be really simple niggunim. But they're not the ones that excite me at all.' Similarly, Adam points out that niggunim may turn into 'oversimplified musical styles that feel a little embarrassing sometimes'. Micah relates this critique as well:

Sometimes there is a bit of a critique, that it's happy-clappy, that it's a bit meaningless, a bit facile and artificial. And yes, it sometimes feels a bit like that. And that may be why I don't do it a lot, just occasionally when it feels right I'll use niggunim, but not as a routine practice. Because I think maybe that can rob it of some of the specialness.

'It doesn't work for some people, and it really works for others' is how Sarah concludes her view of the practice. Therefore, the balance called for by most of the interviewees rises to the fore, as well as the capacity of prayer leaders and cantors to be able to cater for different tastes and wishes in a congregation. Thus, she claims:

I think it's important especially with niggunim to be OK with knowing that not everyone is going to love it. And learning how to deal with that is hard; it's very hard. But I think it is important because it shows just how emotionally connected music can be for people.

\section{Conclusions}

Summarising the analysis presented above of the functions and motives related to contemporary progressive Jewish involvement in niggunim, it seems that wordless songs may facilitate and inspire new forms of prayer and practice in the progressive communities to some extent, as presumed by Jody Myers (2011: I 83-4). There are similarities in the functions of niggunim in the past and present - for example their ability to create atmosphere, community and prepare for prayer - but there are also significant differences, especially related to the mystical aspects of the practice.

As I have argued elsewhere (Illman 20I6), the informants are reluctant to term their engagement with niggunim a revival or rekindling of the Hasidic tradition. Rather, they look at the tradition as 'a source which is available' (Daniel) - to use and be inspired by, but not as a historical legacy that needs to be, or even should be, recreated as faithfully as possible. Some aspects of the tradition are accepted as positive and innovative. These include the meditative 
and embodied functions of niggunim, the joyous expression as well as the creative, bricolage approach of the Hasidim, which seems to suit contemporary religious preferences well, mixing and matching tunes from sacred and secular sources, popular culture and contemporary influences. Other aspects are however consciously rejected, a prominent example being the ecstatic traits of niggunim. Another significant difference concerns who is singing. Within Hasidic traditions, niggunim are an exclusively male phenomenon (Idelsohn I 992: 432, 434). The interviewees have a different view, though, and as a contrast, the niggunim of progressive London are sung by women and men together.

The attraction and inspiration of the historical Hasidic niggunim practices is thus performative rather than theological. Function seems more relevant than origin when it comes to choosing a tune and, hence, contemporary niggunim singing does not necessarily carry the same connotations as the historic, Hasidic counterpart it is modelled on (Summit 2000: 47,88). As the practice is situated in a new frame, the music becomes the carrier of new connotations (Hoondert 2015: I 26). The interviewees give voice to a wish to find a way of deepening their religiosity within the frames of the Jewish tradition while simultaneously refusing to be held back by the traditional structures of Jewish identity (e.g. institutions, ethnicity, language and gender) in their searches for a comprehensive, personally relevant and meaningful way of being Jewish. 'Music has the power to create a discourse that mixes signifiers and juxtaposes meanings', Philip Bohlman contends (Bohlman 2008: 69). In my opinion, this statement aptly summarises the views of niggunim presented in this article.

Dr Ruth IIIman is Director of the Donner Institute for Research in Religious and Cultural History, and docent of Comparative Religion at Åbo Akademi University. She is committed to research on religion and the arts, interreligious dialogue and contemporary Judaism. Her work has been published and reviewed in journals such as Journal of Contemporary Religion, Studies in Interreligious Dialogue and Journal of the American Academy of Religion. Her recent books include Art and Belief: Artists Engaged in Interreligious Dialogue (Equinox Publications, 2012) and Theology and the Arts: Engaging Faith, co-authored with W. Alan Smith (Routledge, 2013).

\section{References}

\section{Ethnographic material}

Ten interviews conducted in North London, 8 July and I 7-2 I November 2014 by the author. All interviews were recorded on $\mathrm{mp}_{3}$ and transcribed into text documents. Recordings and transcripts are stored at the Folklore Archive, Åbo Akademi University, Turku, Finland. Archive codes: IF mgt 2014/O28 and IF mgt 2014/032-040. 
Bibliography

Avenary, Hanoch, 2009. 'The Hasidic niggun: ethos and melos of a folk liturgy', Journal of Synagogue Music, 43, pp. 48-54

Bohlman, Philip V., 2008. Jewish Music and Modernity (Oxford University Press)

Edelman, Marsha B., 2003. Discovering Jerwish Music (Philadelphia, Jewish Publications Society)

Elbogen, Ismar, I 993. Jewish Liturgy: A Comprehensive History (Philadelphia, Jewish Publication Society)

Gartner, Lloyd P. et al., 2007. 'Hasidism' in Encyclopaedia Judaica, vol. 8, eds Michael Berenbaum and Fred Skolnik, 2nd edn (Detroit, Macmillan Reference), pp. 393-434

Hackett, Rosalind, 20 I 2. 'Sound, music, and the study of religion', Temenos: Nordic Journal of Comparative Religion, 48(I), pp. I I-27

HaCohen, Ruth, 20 I I. The Music Libel against the Jerws (New Haven, Yale University Press)

Hoondert, Martin, 20 I 5. 'Musical religiosity', Temenos: Nordic Journal of Comparative Religion, 5 I (I), pp. I 23-36

Huss, Boaz, 2007. 'The New Age of Kabbalah: contemporary Kabbalah, the New Age and postmodern spirituality', Journal of Modern Jewish Studies, 6(2), pp. 107-25

Idelsohn, Abraham Z., ( 1 929) I 992. Jerwish Music in its Historical Development (New York, Dover Publications)

Illman, Ruth, 20 I 5 . 'Singing a wordless niggun: contemporary Jewish experiences', conference paper presented at Magnified and Sanctified: The Music of Jewish Prayer (University of Leeds)

2016. 'Practices of niggunim: contemporary Jewish song in a vernacular religious perspective' in Contesting Authority, eds Marion Bowman and Ülo Valk (London, Equinox Publications), forthcoming

Jacobs, Louis, (1972) I 993. Hasidic Prayer (London, The Littman Library of Jewish Civilization)

Jastrow, Marcus, 2004. Dictionary of the Targumim, Talmud Bavli, Talmud Yerushalmi and Midrashic Literature (New York, Judaica Treasury)

Kahn-Harris, Keith, and Marcus Moberg, 20 I 2. 'Religious popular music: between the instrumental, transcendent and transgressive, Temenos: Nordic Journal of Comparative Religion, 48(I), pp. 87-106

Laack, Isabel, 20 I 5 . 'Sound, music and religion: a preliminary cartography of a transdisciplinary research field', Method and Theory in the Study of Religion, 27(3), pp. $220-46$

Levine, Joseph A., 2009. 'The issue of niggunim in worship: too much of a good thing?', Journal of Synagogue Music, 43, pp. 4-7

Meir, Jonatan, 2010. 'The imagined decline of Kabbalah: the kabbalistic yeshiva Sha'ar Ha-Shamayim and Kabbalah in Jerusalem in the beginning of the 
twentieth century' in Kabbalah and Modernity: Interpretations, Transformations, Adaptations, eds Boaz Huss, Marco Pasi, and Kocku von Stuckrad (Leiden, Brill), pp. I 97-220

Myers, Jody, 20 I I. 'Kabbalah at the turn of the $2 \mathrm{I}^{\text {st }}$ century', in Jerwish Mysticism and Kabbalah: New Insights and Scholarship, ed. Frederick. E. Greenspahn (New York University Press), pp. I75-90

Nynäs, Peter, Ruth Illman, and Tuomas Martikainen, (eds) 2015. In the Outskirts of 'the Church': Diversities, Fluidities and New Spaces of Religion in Finland (Zurich, LIT Verlag), forthcoming

Ochs, Vanessa L., 2007. Inventing Jerwish Ritual (Philadelphia, Jewish Publication Society)

Rubin, Emanuel, and John H. Baron, 2006. Music in Jerwish History and Culture (Sterling Heights, Harmonie Park Press)

Rubinstein, Aryeh (ed.), I 975. Hasidism (Jerusalem, Keter Books)

Smith, Chani Haran, 20 Io. Tuning the Soul: Music as a Spiritual Process in the Teachings of Rabbi Nahman of Bratzlav (Leiden, Brill)

Summit, Jeffrey A., 2000. The Lord's Song in a Strange Land: Music and Identity in Contemporary Jewish Worship (Oxford University Press)

Weiss, Sam, 2009. 'Carlebach, neo-Hasidic music and liturgical practice', Journal of Synagogue Music, 43, pp. 55-75.

Weissler, Chava, 20 r r. 'Performing Kabbalah in the Jewish Renewal Movement' in Kabbalah and Contemporary Spiritual Revival, ed. Boaz Huss (Negev, Ben Gurion University of the Negev Press), pp. 39-74 